\title{
HABITAÇÃO E SAÚDE: ABORDAGENS NAS PUBLICAÇÕES ACADÊMICAS NACIONAIS E DA LÍNGUA INGLESA
}

\author{
Beatriz Ferreira de Carvalho' \\ Natália Barboza Helbusto ${ }^{2}$ \\ Paula Vilhena Carnevale Vianna ${ }^{3}$
}

\begin{abstract}
Resumo: O conceito ampliado de saúde, estabelecido pela Organização Mundial de Saúde, considera o meio de vida, incluindo a qualidade da habitação. No Brasil, o déficit habitacional é significativo e as políticas públicas, na forma de programas habitacionais, vêm favorecendo a implantação de condomínios residenciais para as classes menos favorecidas. Este estudo investigou de que forma a produção acadêmica nacional e de países de língua inglesa abordam a relação saúde/habitação para as populações mais pobres. Trata-se de estudo de revisão bibliográfica de artigos científicos que apresentassem como palavras chave os termos "housing" e "health" e "saúde" e "habitação". Observou-se diferenças na produção, com maior número de publicações críticas em relação às políticas habitacionais e seus efeitos deletérios para a saúde das populações na língua inglesa. Este é um campo pouco explorado na área da saúde no Brasil e necessário para a efetivação da saúde em seu sentido ampliado, como previsto na Constituição Brasileira.

Palavras-chave: Habitação; Área de risco; Saúde; Qualidade de vida.
\end{abstract}

\footnotetext{
1 Biomedicina/Universidade do Vale do Paraíba, Brasil. E-mail: beatrizcarvalho182@hotmail.com.

2 Planejamento e Desenvolvimento Urbano/Universidade do Vale do Paraíba, Brasil. E-mail: natalia.helbusto@hotmail.com.

3 Planejamento e Desenvolvimento Urbano/Universidade do Vale do Paraíba, Brasil. E-mail: paulavianna@univap.br.
} 